\title{
ROBERTO GONZÁLEZ HERRERA A 16 AÑOS DE SU GESTA POR LA DEFENSA DEL DERECHO A LA EDUCACIÓN PÚBLICA UNIVERSITARIA (BREVE REPORTAJE DE LA JORNADA ROBERTO GONZÁLEZ
} HERRERA, 13 AL 20 DE ABRIL DE 2015)

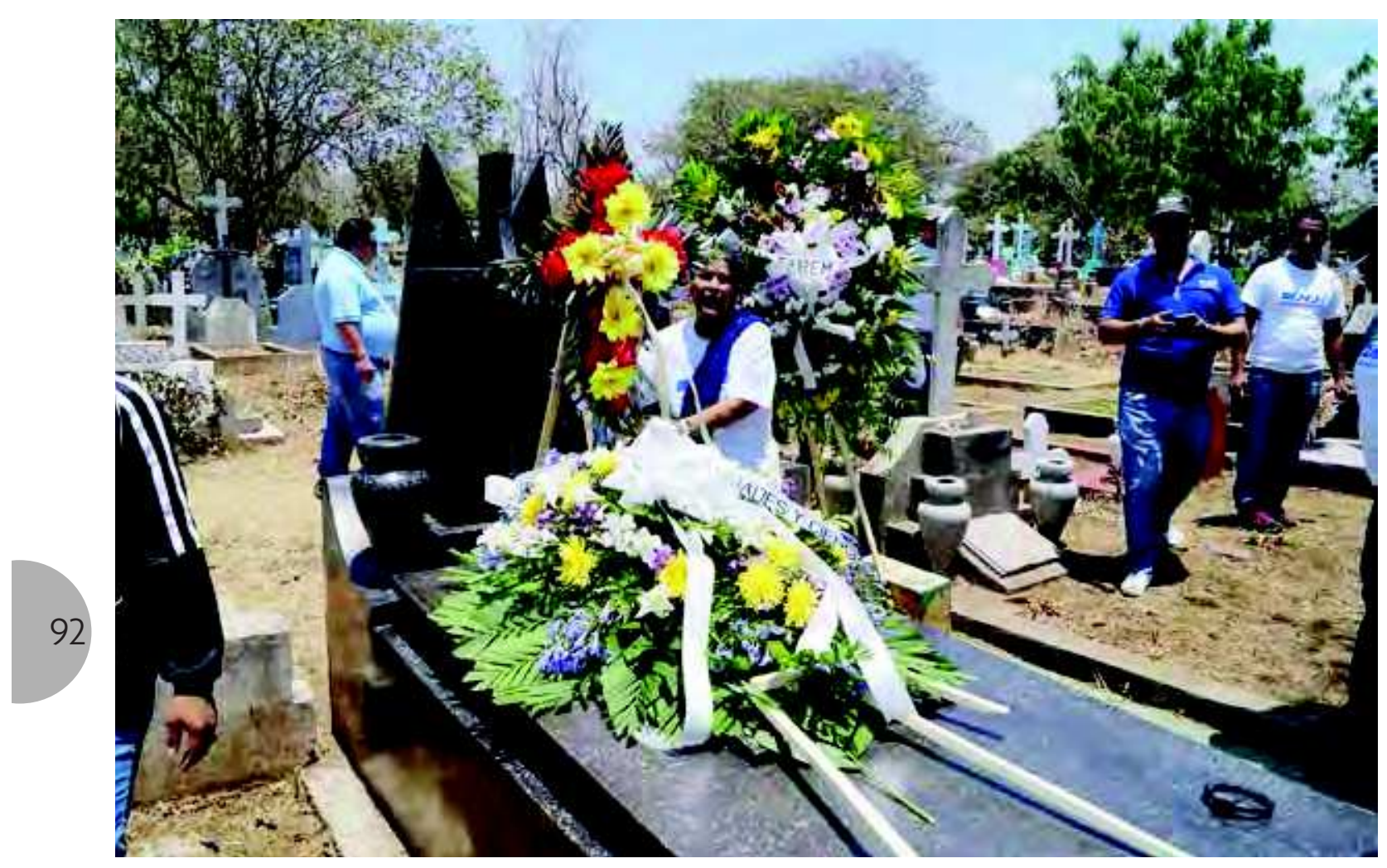

La Universidad Nacional Autónoma de Nicaragua, Managua, UNAN-Managua por medio de las máximas autoridades de decanato, dirigencia de UNEN, personal administrativo y estudiantes en general de la Facultad de Humanidades y Ciencias Jurídicas realizó distintas actividades en conmemoración al décimo sexto aniversario del asesinato del joven mártir Roberto González Herrera, quien el 20 de abril de 1999 ofrendó su vida por la lucha justa por el $6 \%$.

La UNAN-Managua y comunidad universitaria de Nicaragua en general lamentaron la muerte de González y los lesionados en aquellas memorables jornadas por la defensa de la educación pública. Cabe recordar que esta tragedia ocurrió en las instalaciones del Banco Central de Nicaragua, durante el gobierno del gobierno neoliberal Arnoldo Alemán.

Como una forma de honrar la gesta de este mártir por el $6 \%$ la comunidad universitaria año con año realiza una semana cultural conmemorativa recordando las gestas universitarias, destacando la entrega de Roberto González. Durante estos días, los jóvenes de primer ingreso de la UNAN-Managua, participan en diversas actividades donde se da a conocer la vida del joven estudiante mártir.

El departamento de Educación Física y Deportes organizó una jornada deportiva donde participaron diversas disciplinas. Seguidamente, se realizó una caminata corta dentro del Recinto Universitario Rubén Darío, encabezada por la Decana de la Facultad de Humanidades y Ciencias Jurídicas, MSc Gloria López Alvarado, en conjunto con estudiantes, personal administrativo y docentes. 
De igual forma, el movimiento estudiantil representado por UNEN realizó un foro debate sobre la vida de Roberto González y su legado. Se analizó la importancia de los estudiantes en la defensa de la educación universitaria pública, y todo el esfuerzo realizado por generaciones de estudiantes, dando su sangre y vida como González por esta reivindicación histórica por el $6 \%$ y por una mejor calidad de la educación.

También se realizó una exposición fotográfica de los héroes y mártires de la Revolución Popular Sandinista y de los jóvenes caídos por las defensa del 6\%. Paralelo a esto se realizaron dos festivales culturales, en la que jóvenes de diversas carreras hicieron gala de sus talentos por medio de bailes, música y otros números especiales. La actividad se realizó en el parqueo ubicado frente al pabellón 30 del Departamento de Derecho y en el Auditorio Fernando Gordillo.

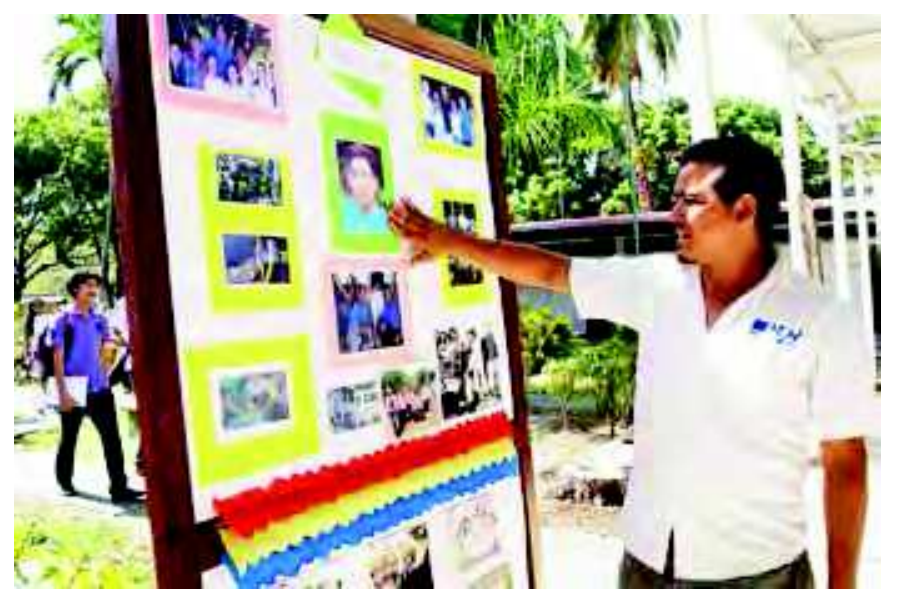

Para finalizar la semana conmemorativa a Roberto González y como viene siendo una costumbre cada año, la Facultad de Humanidades y Ciencias Jurídicas y el Movimiento Estudiantil UNEN, organizaron una caminata fuera del campus universitario, en la cual participaron todas las unidades académicas de la Universidad, incluyendo delegaciones de León y de otras universidades pertenecientes al CNU. La marcha partió del Centro Cívico (ZUMEN), hasta llegar a las instalaciones del Banco Central de Nicaragua, realizándose un acto justo en el lugar donde cayera el mártir Roberto González.

Entre consignas, música, pancartas y mucho entusiasmo juvenil, personal administrativo, docentes, estudiantes, de las diferentes universidades participantes marcharon en una mañana soleada.

Es importante destacar que además de la delegación de la UNAN-León, participaron de la Universidad Nacional de Ingeniería (UNI), la Facultad Regional
Multidisciplinaria de Carazo FAREM-Carazo, entre otras.

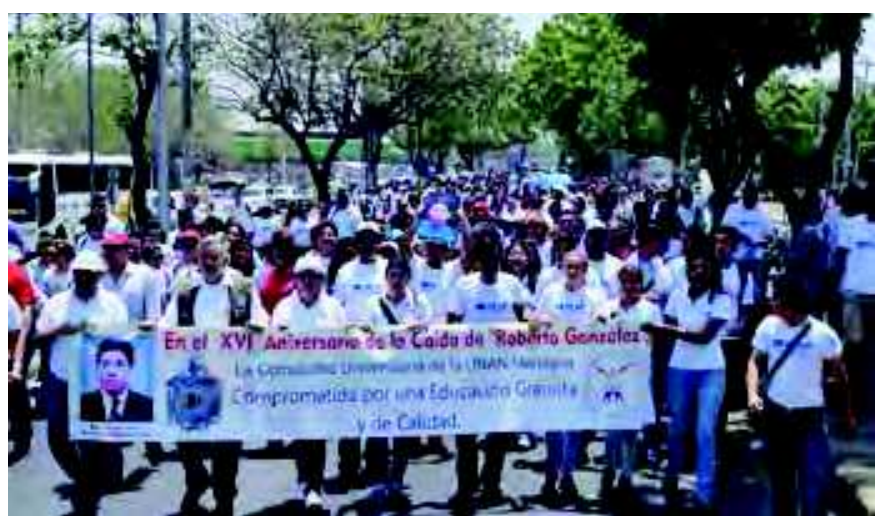

Otros de los participantes en la marcha, fue el Rector de la Universidad Nacional Agraria (UNA) y presidente del Consejo Nacional de Universidades (CNU), Ingeniero Telémaco Talavera, quien estuvo acompañado de la Rectora de la UNAN-Managua, maestra Ramona Rodríguez y resto de autoridades universitarias, entre ellos el Secretario General, doctor Luis Alfredo Lobato Blanco, ex decano de la Facultad de Humanidades y Ciencias Jurídicas. Durante el acto en las instalaciones del Banco tomo la palabra el Presidente del CNU, Ingeniero Telémaco Talavara, la Rectora de la UNAN-Managua, Msc Ramona Rodríguez y el Presidente del Banco Central, Dr. Ovidio Reyes.

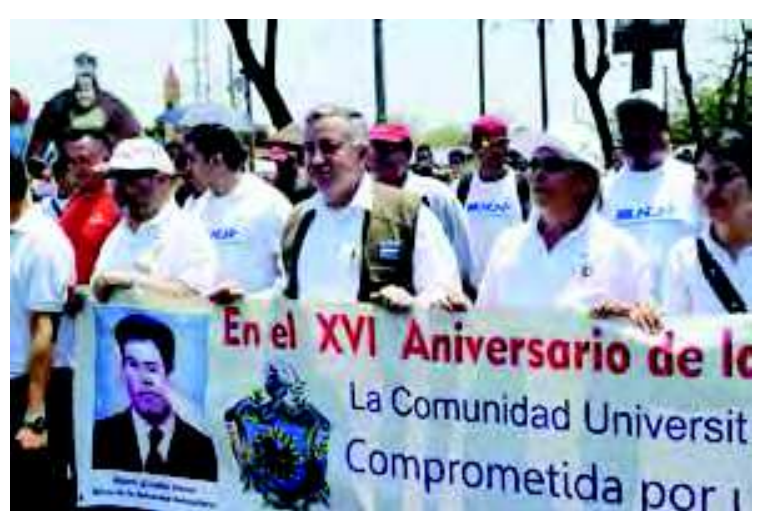

Durante el acto se procedió a develar un busto en el sitio donde falleció el estudiante de Derecho, Roberto González Herrera, como homenaje a su memoria y de las luchas sociales y estudiantiles. Como cierre, una caravana de buses y vehículos partió en dirección al Cementerio Oriental, donde igualmente cada año, se lleva ofrendas florales a la tumba de Roberto González. De regreso del cementerio y en auditorio que lleva el nombre del mártir se presentó un video alusivo a los acontecimientos de 1999 donde perdiera la vida Roberto. 


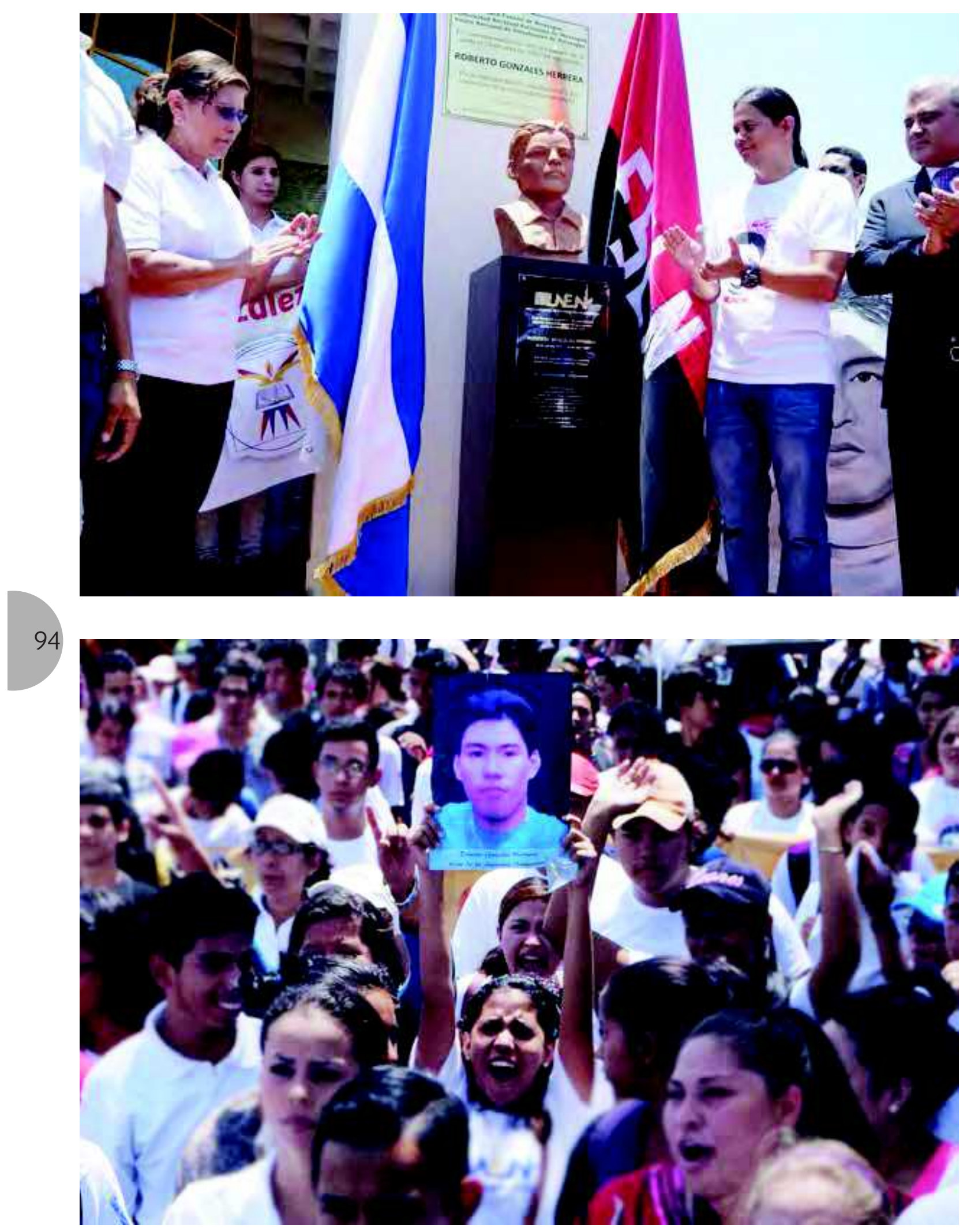

